\title{
Etnobotânica de Plantas Medicinais no Assentamento Monjolinho, município de Anastácio, Mato Grosso do Sul, Brasil
}

\author{
Simone Alves da Cunha ${ }^{1,3}$ e Ieda Maria Bortolotto ${ }^{2}$
}

Recebido em 25/03/2011. Aceito em 4/07/2011

\begin{abstract}
RESUMO
(Etnobotânica de Plantas Medicinais no Assentamento Monjolinho, município de Anastácio, Mato Grosso do Sul, Brasil). O objetivo desse trabalho foi realizar um estudo etnobotânico sobre as plantas medicinais utilizadas pelos moradores do assentamento Monjolinho, Anastácio, Mato Grosso do Sul. Foram entrevistados através do método bola de neve 35 moradores (33 mulheres). As espécies (210) pertencem a 72 famílias, destacando-se as nativas do Cerrado, sendo o restante cultivado próximos das casas. Fabaceae e Asteraceae foram as mais citadas. Das 23 espécies de Fabaceae, 20 são nativas. As espécies que obtiveram o maior número de citações foram jatobá (Hymenaea spp.) e o barbatimão (Stryphnodendron obovatum Benth.) e as com índice de concordância de uso (CUP) alto foram barbatimão (S. obovatum) e cancorosa (Maytenus ilicifolia (Schrad.) Planch). As folhas foram as partes mais utilizadas. As doenças do aparelho respiratório e geniturinário foram as mais citadas. A diversidade $\left(H^{\prime}=5,03\right)$ de uso das espécies é alta. O conhecimento foi adquirido entre amigos (37\%), cursos (17\%) ou família (39\%) e mostra que, ao longo do tempo, há expressivo aproveitamento das espécies medicinais e conhecimento da comunidade.
\end{abstract}

Palavras-chave: Cerrado, espécies nativas, transmissão de conhecimento

\begin{abstract}
(Ethnobotany of medicinal plants in the Monjolinho settlement, Anastácio, Mato Grosso do Sul, Brazil). This work carried out an ethnobotanical survey of the medicinal plants used by the inhabitants of the Monjolinho settlement in Anastácio city, in the state of Mato Grosso do Sul. The goal of this work was to verify how residents congregate information brought from their place with information obtained where they live now, and to verify how the knowledge of spontaneous and native species from cerrado varies in relation to the specie cultivated. A total of 35 inhabitants were interviewed using the snowball method ( 33 women). The species (210) recorded belong to 72 families. Of these, many are native Cerrado species and the remaining species are cultivated next to the houses. Fabaceae and Asteraceae were the most cited families. Of the 23 species of Fabaceae, 20 are native. The species with the highest number of citations were jatobá (Hymenaea spp.) and barbatimão (Stryphnodendron obovatum Benth.). Those with a high agreement index of use (CUP) were barbatimão (S. obovatum) and cancorosa (Maytenus ilicifolia (Schrad.) Planch). Leaves represented the most used parts. Diseases of the respiratory and genitourinary systems were cited. The species use diversity ( $\mathrm{H}^{\prime}$ $=5,03)$ was high. The information was acquired from friends $(37 \%)$, courses $(17 \%)$ or family $(39 \%)$, and shows that there is use of medicinal species, and knowledge about these plants, in the community.
\end{abstract}

Key words: cerrado, native species, transmission of knowledge

\section{Introdução}

Estudos etnobotânicos têm sido desenvolvidos com o objetivo de registrar o saber botânico tradicional particularmente relacionado ao uso dos recursos da flora (Guarim Neto et al. 2000). Eles indicam como as pessoas afetam a biologia de determinadas populações de plantas, não apenas sob aspectos negativos, mas beneficiando e promovendo os recursos manejados (Albuquerque \& Andrade 2002). Comunidades que ocupam ambientes diversificados, e com grande número de espécies, têm oportunidades de explorar uma gama maior de recursos (Amorozo 1996). É o caso do Cerrado que abriga 30\% da diversidade do país (Pagotto et al. 2006) e ocupa cerca de $23 \%$ do território brasileiro. Sua flora é considerada a mais rica entre as savanas do mundo (Mendonça et al. 1998), mas é pouco conhecida e há carência

\footnotetext{
${ }^{1}$ Universidade Federal de Mato Grosso do Sul, Programa de Pós-Graduação em Biologia Vegetal, Campo Grande, MS, Brasil

${ }^{2}$ Universidade Federal de Mato Grosso do Sul, Centro de Ciências Biológicas e da Saúde, Departamento de Biologia, Laboratório de Botânica, Campo Grande, MS, Brasil

${ }^{3}$ Autora para correspondência: simone_msa@hotmail.com
} 
de estudos voltados para a identificação de plantas úteis, principalmente se consideradas sua rica diversidade e área ocupada (Guarim Neto \& Morais 2003).

Os estudos etnobotânicos têm sido desenvolvidos em diversas regiões brasileiras por Prance (1987), Albuquerque \& Andrade (2002), Pasa et al. (2005) e Miranda \& Hanazaki (2008). No Cerrado pode-se destacar os trabalhos de Guarim Neto \& Morais (2003), Vila Verde et al. (2003), Souza (2007), Silva \& Proença (2008), entre outros. No Mato Grosso do Sul trabalhos como os de Pott \& Pott (1994) trazem informações sobre diversas espécies do Cerrado que ocorrem também no Pantanal; Schardong \& Cervi (2000); Nunes et al. (2003); Bueno et al. (2005) e Alves et al. (2008) mostram o grande conhecimento da população, como também evidenciam a carência destes estudos no Estado.

Segundo Oliveira et al. (2009), no Brasil, dentre as diversas categorias de usos da flora, há um predomínio de trabalhos com plantas medicinais. Amorozo \& Gély (1988), Milliken \& Albert (1996), Amorozo (2002), Begossi et al. (2002), Guarim Neto \& Morais (2003), Ming \& Amaral-Junior (2005) e Pinto et al. (2006) tratam da importância das plantas medicinais para as populações estudadas por eles. A abordagem desse tema permite planejar a pesquisa a partir de um conhecimento empírico já existente, e muitas vezes consagrado pelo uso contínuo, que deverá então ser testado em bases científicas (Amorozo 1996). O reconhecimento e o resgate do saber local sobre as plantas medicinais são fundamentais em comunidades rurais, pois os remédios caseiros surgem como alternativa de cura, muitas vezes a única devido à falta de outros recursos para cuidar da saúde. A utilização é menos onerosa e mais acessível, como foi verificado por Silva \& Proença (2008) para famílias de baixo poder aquisitivo e quando há pouca infra-estrutura em saúde.

O conhecimento sobre o uso de plantas é transmitido oralmente de geração a geração (Amorozo 1996) por um processo de aquisição de comportamento, atitudes ou tecnologias, através da impressão, do condicionamento, imitação, ensino e aprendizagem, ou combinações destes fatores (Cavalli-Sforza et al. 1982). Pode ocorrer através do contato dos membros mais velhos com os mais novos, na socialização no interior do próprio grupo doméstico e de parentesco na transmissão vertical ou entre sujeitos da mesma geração na transmissão horizontal (Cavalli-Sforza et al.1982; Boesch \& Tomasello1998; Lozada et al. 2006).

Miranda e Hanazaki (2008) relatam a importância de analisar as particularidades do conhecimento ecológico local, que é em grande parte mediado pelo contexto atual destas comunidades. Os assentamentos rurais constituem-se como novos espaços de sociabilidade que se espalham por todo o interior do país (D’Aquino 1998). São locais onde se define e se transforma a história coletiva da população rural (Cappellin \& Castro 1997). Nestas áreas, estudos etnobotânicos são importantes, pois permitem avaliar de que forma os moradores reúnem as informações trazidas de seus locais de origem com as obtidas no lugar onde se instalaram, mostrando como eles incorporam os novos, pois, oriundos de diversas regiões do país, necessitam adaptar-se e buscam, nesse novo ambiente plantas úteis as suas necessidades.

O objetivo deste trabalho foi realizar um estudo etnobotânico sobre as plantas medicinais utilizadas pelos moradores do assentamento Monjolinho no município de Anastácio, Mato Grosso do Sul.

\section{Material e métodos}

\section{Área de estudo}

O Assentamento Monjolinho localiza-se no município de Anastácio, MS, na porção centro-oeste do estado, a 138

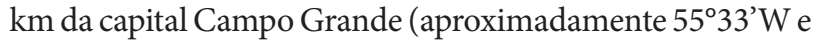
$20^{\circ} 46^{\prime} \mathrm{S}$ ). A vegetação predominante é o Cerrado (lato sensu) ainda conservado em pequenas manchas nos lotes, ou em áreas maiores de preservação permanente e reservas legais.

O assentamento é formado por 291 lotes (maioria de 20 a 50 ha) distribuídos em aproximadamente 9.500 hectares. $\mathrm{A}$ área pertencia à Rede Ferroviária Federal Sociedade Anônima (RFFSA), que exercia a extração de madeira para as máquinas e de lastro para ferrovia, arrendamento para criação de gado e reflorestamento. Em outubro de 1988 a fazenda Monjolinho foi liberada para realização de assentamento provisório. Em dezembro de 1988, o INCRA (Instituto Nacional de Colonização e Reforma Agrária) criou o Plano de Assentamento Monjolinho e em 1990, as famílias receberam os lotes. Dos 291 lotes, 285 foram destinados aos assentados, cinco para implantação de escolas e um para o núcleo urbano (Incra 1990).

Essa área é utilizada para agropecuária, em regime de economia familiar. Nos lotes a exploração do solo é feita com predomínio de pastagens, pois a base de economia é a produção de leite. Também ocorre a criação de gado bovino de corte e plantação de algumas culturas para subsistência, como mandioca, milho, melancia, abóbora, maxixe e feijão. A maioria dos moradores tem origem na área rural e participou de acampamentos de sem terra. Na comunidade existe um posto de saúde com um enfermeiro que na maioria das vezes encaminha os pacientes para o hospital mais próximo na cidade de Anastácio.

\section{Métodos}

Os dados foram coletados de abril de 2008 a novembro de 2009. No início do trabalho foi organizada uma reunião com a comunidade para apresentar o projeto e seus objetivos e obtenção do consentimento da comunidade para o desenvolvimento do trabalho. Posteriormente o trabalho foi submetido e aprovado pelo Comitê de Ética em Pesquisa com Seres Humanos da UFMS (Resolução 196/96 do Conselho Nacional de Saúde) e enviado ao Conselho de Gestão do Patrimônio Genético (CGEN), para consulta sobre a necessidade de autorização. Após análise, foi dispensado de autorização daquele órgão, uma vez o assentamento não se caracteriza 
como "comunidade local" presente no inciso III do art. $7^{\circ}$ da Medida Provisória n 2.186-16/2001 e sim, como comunidade de pequenos agricultores / agricultores familiares.

Foram realizadas entrevistas semi-estruturadas baseadas em um formulário, com o uso do método bola de neve (Bernard 1995). À medida que os entrevistados informaram as plantas por eles utilizadas, essas foram coletadas com o acompanhamento do informante herborizadas, montadas, identificadas e incorporadas ao Herbário (CGMS) da Universidade Federal de Mato Grosso do Sul. As identificações botânicas foram realizadas por comparação com material depositado no herbário, por consulta à literatura pertinente e especialistas.

A grafia dos nomes científicos foi conferida utilizando a base de dados Tropicos, disponível em http://www.tropicos. org. Para a listagem dos táxons seguiu-se o APG III (2009). Sobre o local de origem das plantas coletadas considerou-se espontâneas as espécies nativas do Cerrado citadas na listagem da flora vascular (Mendonça et al.1998) e/ou Guarim Neto \& Morais (2003) na compilação de dados sobre espécies medicinais nativas, e como cultivadas as que são plantadas pelos moradores nas áreas manejadas, como quintais e roças.

As doenças citadas pelos entrevistados foram categorizadas de acordo com o CID-10 - Classificação estatística internacional de doenças e problemas relacionados à saúde.

Além da descrição qualitativa dos resultados, foi calculada a importância relativa das espécies citadas na comunidade, por meio da concordância quanto ao uso principal (CUP) e concordância quanto ao uso principal corrigida (CUPc) Amorozo \& Gély (1988), modificado de Friedman et al. (1986). Foi calculado também o índice de diversidade de Shannon-Wiener e o índice de equitabilidade, que permitem comparações entre a diversidade do conhecimento etnobotânico de diferentes comunidades (Begossi 1996).

As fórmulas usadas para calcular o índice de diversidade de Shannon-Wiener e o índice de equitabilidade:

$$
\mathrm{H}^{\prime}=-\Sigma(\mathrm{pi})\left(\mathrm{LN} \text { pi) } \quad \mathrm{e}=\mathrm{H}^{\prime} / \log 2 \mathrm{~S}\right.
$$

Onde: $\mathrm{S}=$ número de espécies; $\mathrm{pi}=\mathrm{ni} / \mathrm{N} ; \mathrm{ni}=$ número de citações por espécie; $\mathrm{N}$ = número total de citações; $H^{\prime}=$ índice de diversidade; $\mathrm{e}$ = índice de equitabilidade de Pielou.

\section{Resultados e discussão}

Foram entrevistadas 35 pessoas, que citaram 209 espécies de plantas medicinais (Tab. 1), distribuídas em 70 famílias botânicas, sendo as mais representativas Fabaceae (23), Asteraceae (20), Lamiaceae (9), Poaceae (9), Euphorbiaceae (7) e Myrtaceae (7). Juntas reúnem 35,9\% do total de espécies citadas (Fig. 1). Resultados semelhantes onde Fabaceae e Asteraceae foram as famílias com maior número de espécies foram encontrados por Guarim Neto \& Moraes (2003) para o Cerrado Mato - Grossense; Ming \& AmaralJunior (2005) na Amazônia e Amorozo (2002) no Pantanal e para Mato Grosso do Sul, Bueno et al. (2005).

Das 23 espécies citadas pertencentes à família Fabaceae, 20 são nativas do Cerrado. Esta é a família com maior núme- ro de espécies do Cerrado (Mendonça et al. 1998). Segundo Guarim Neto \& Moraes (2003), quanto maior o número de espécies em uma família, maior a probabilidade de que estas venham a ser utilizadas por populações humanas que façam uso dos recursos da flora nativa. Asteraceae é a maior família das Eudicotiledôneas e tem uma distribuição cosmopolita; no Brasil são particularmente comuns nas regiões abertas, principalmente no Cerrado e em florestas secundárias (Souza \& Lorenzi 2005).

Dos 35 entrevistados, 33 são mulheres, demonstrando o interesse delas por essa categoria de plantas no assentamento, também observado nos trabalhos de Begossi et al. (2002); Kainer \& Duryea (1992), Figueiredo et al. (1993) e Caniago \& Siebert (1998). Cappellin \& Castro (1997) mostram que nos assentamentos estudados as mulheres eram trabalhadoras rurais, donas de casa, mães, responsáveis pela roça, pela horta e pequenas criações. No presente estudo, além dessas ocupações, elas mostraram grande conhecimento e que entram no Cerrado para buscar as plantas medicinais que precisam. Além disso, têm uma organização social (reuniões e trocas de experiências) sobre plantas com uso medicinal. Durante a formação do assentamento elas participaram de cursos oferecidos pela Pastoral da Terra sobre "medicina alternativa", onde receberam informações sobre plantas medicinais e até hoje mantêm essa tradição.

Para verificar a importância relativa das plantas utilizadas no assentamento quanto ao número de informantes que as citaram e à concordância dos usos citados, foram listadas as plantas mencionadas por treze ou mais informantes (Tab. 2), totalizando 17 espécies. Pode-se observar que das quatro espécies que tiveram um índice de concordância de uso (CUP) alto (de $80 \%$ ou mais), três são nativas do Cerrado, como Stryphnodendron obovatum (barbatimão), utilizada na cicatrização de feridas, Maytenus ilicifolia (cancorosa), utilizada como depurativo do sangue, e Hymenaea spp. (jatobá), utilizada em tosses, resfriados e bronquite. Mesmo aplicando o fator de correlação, o CUP corrigido continua alto (próximo de 70\%). Esses dados são diferentes dos obtidos por Pilla et al. (2006) e Pinto et al. (2006), onde as espécies que tem CUP alto são espécies cultivadas.

As espécies que obtiveram o maior número de citações foram jatobá (Hymenaea spp.) e o barbatimão (Stryphnodendron obovatum) cujas cascas são utilizadas para o tratamento de doenças. Duas espécies de jatobá foram identificadas para o local (Hymenaea stigonocarpa e H. martiana), mas os moradores não fizeram distinção dessas espécies. As partes mais utilizadas foram: folhas $(42 \%)$,) seguidas por raízes (21\%), casca e entrecasca (21\%), frutos (5,3\%), sementes $(5,1 \%)$, planta inteira $(3,5 \%)$ e outros. As folhas são as mais citadas em diversos trabalhos sobre plantas medicinais como Schardong \& Cervi (2000), Pilla et al. (2006) e Medeiros et al. (2004). O maior número de citações do jatobá e do barbatimão pode explicar o fato da casca ser uma das partes mais utilizadas. A maioria das raízes utilizadas era de ervas ou subarbustos. 
Tabela 1. Lista das espécies medicinais citadas pelos moradores do Assentamento Monjolinho, Anastácio, MS. Ref = número de registro do herbário; $\mathrm{c}=$ cultivada; $\mathrm{n}=$ nativa.

\begin{tabular}{|c|c|c|c|}
\hline Familia/Espécie & Nome Popular & Ref & C ou N \\
\hline \multicolumn{4}{|l|}{ ACANTHACEAE } \\
\hline Justicia pectoralis Jacq. & doutorzinho, novalgina, dipirona, doril & 28599 & $\mathrm{C}$ \\
\hline \multicolumn{4}{|l|}{ ADOXACEAE } \\
\hline Sambucus sp. & sabugueiro & - & $\mathrm{C}$ \\
\hline \multicolumn{4}{|l|}{ AGAVACEAE } \\
\hline Herreria salsaparilha Mart. & salsaparrilha & 28660 & $\mathrm{~N}$ \\
\hline Furcraea foetida (L.) Haw. & piteira, sisal, pita & - & $\mathrm{C}$ \\
\hline \multicolumn{4}{|l|}{ ALISMATACEAE } \\
\hline Echinodorus macrophyllus (Kunth) Micheli & chapéu-de-couro & 28642 & $\mathrm{~N}$ \\
\hline \multicolumn{4}{|l|}{ ALLIACEAE } \\
\hline Allium sativum $\mathrm{L}$. & alho & - & $\mathrm{C}$ \\
\hline \multicolumn{4}{|l|}{ AMARANTHACEAE } \\
\hline Alternanthera brasiliana (L.) Kuntze & terramicina & 28591 & $\mathrm{~N}$ \\
\hline Alternanthera pungens Kunth & anador & 28596 & $\mathrm{C}$ \\
\hline Chenopodium ambrosioides L. & mentruz, erva-de-santa-maria & 28593 & $\mathrm{~N}$ \\
\hline Gomphrena celosioides Mart. & perpétua, perpétua-do-campo & 28629 & $\mathrm{~N}$ \\
\hline Gomphrena globosa L. & perpétua- roxa & 28662 & $\mathrm{~N}$ \\
\hline \multicolumn{4}{|l|}{ ANACARDIACEAE } \\
\hline Anacardium humile A. St.-Hil. & caju-do-campo, cajuzinho-do-campo & 28664 & $\mathrm{~N}$ \\
\hline Anacardium occidentale L. & caju & 28610 & $\mathrm{C}$ \\
\hline Mangifera indica $\mathrm{L}$. & manga & - & $\mathrm{C}$ \\
\hline Myracrodruon urundeuva Allemão & aroeira & 28663 & $\mathrm{~N}$ \\
\hline Schinus terebinthifolia Raddi & pimenta-do-reino-de-árvore & 28698 & $\mathrm{~N}$ \\
\hline \multicolumn{4}{|l|}{ ANNONACEAE } \\
\hline Annona cornifolia A. St.-Hil. & pinha-do-cerrado & 28622 & $\mathrm{~N}$ \\
\hline Annona muricata $\mathrm{L}$. & graviola & 28726 & $\mathrm{C}$ \\
\hline Xylopia aromatica (Lam.) Mart. & pimenta-de-macaco & 28638 & $\mathrm{~N}$ \\
\hline \multicolumn{4}{|l|}{ APIACEAE } \\
\hline Anethum graveolens L. & êndio & 28581 & $\mathrm{C}$ \\
\hline Coriandrum sativum $\mathrm{L}$. & coentro & 28588 & $\mathrm{C}$ \\
\hline Petroselinum crispum (Mill.) Fuss & salsinha & - & $\mathrm{C}$ \\
\hline \multicolumn{4}{|l|}{ APOCYNACEAE } \\
\hline Catharanthus roseus (L.) G. Don & boa-noite & 28727 & $\mathrm{C}$ \\
\hline Hancornia speciosa Gomez & mangaba & 28584 & $\mathrm{~N}$ \\
\hline Nerium oleander L. & espirradeira & 28613 & $\mathrm{C}$ \\
\hline \multicolumn{4}{|l|}{ ARACEAE } \\
\hline Colocasia esculenta (L.) Schott & inhame & 28732 & $\mathrm{C}$ \\
\hline Philodendron imbe Schott ex Endl. & cipó-imbé & 28684 & $\mathrm{~N}$ \\
\hline ARECACEAE & & & $\mathrm{N}$ \\
\hline Acrocomia aculeata (Jacq.) Lodd. ex Mart. & bocaiuva & - & \\
\hline Cocos nucifera L. & coco & - & $\mathrm{C}$ \\
\hline \multicolumn{4}{|l|}{ ARISTOLOCHIACEAE } \\
\hline Aristolochia arcuata Mart. & cipó milomem & 28670 & $\mathrm{~N}$ \\
\hline Aristolochia esperanzae Kuntze & jarrinha ou patinho & 28669 & $\mathrm{~N}$ \\
\hline
\end{tabular}


Tabela 1. Continuação.

\begin{tabular}{|c|c|c|c|}
\hline Familia/Espécie & Nome Popular & Ref & C ou N \\
\hline \multicolumn{4}{|l|}{ ASPHODELACEAE } \\
\hline Aloe vera (L.) Burm. f. & babosa & - & $\mathrm{C}$ \\
\hline \multicolumn{4}{|l|}{ ASTERACEAE } \\
\hline Acanthospermum australe (Loefl.) Kuntze & carrapichinho, carrapicho, tapecuê & 28565 & $\mathrm{~N}$ \\
\hline Acanthospermum hispidum DC. & carrapicho-de-carneiro, chifre-de-carneiro & 28566 & $\mathrm{~N}$ \\
\hline Achillea millefolium $\mathrm{L}$. & mil-em-rama ou mil-homens & 28573 & $\mathrm{C}$ \\
\hline Achyrocline sp. & marcelinha-do-campo, marcela, marcela-do-campo & 28681 & $\mathrm{~N}$ \\
\hline Acmella oleracea (L.) R.K. Jansen & anestesiol & 28695 & $\mathrm{~N}$ \\
\hline Ageratum conyzoides $\mathrm{L}$. & mentrasto, confrei, erva-são-joão & 28589 & $\mathrm{~N}$ \\
\hline Artemisia absinthium L. & losna & 28575 & $\mathrm{C}$ \\
\hline Artemisia sp. & pronto-alivio & 28721 & $\mathrm{C}$ \\
\hline Baccharis dracunculifolia DC. & alecrim-do-campo ou vassoura & 28668 & $\mathrm{~N}$ \\
\hline Baccharis trimera (Less.) DC. & carqueja & 28728 & $\mathrm{C}$ \\
\hline Bidens pilosa $\mathrm{L}$. & picão, picão-preto & 28614 & $\mathrm{~N}$ \\
\hline Conyza bonariensis (L.) Cronquist & avoadeira & 28678 & $\mathrm{~N}$ \\
\hline Eupatorium sp. & assapeixe desinchadeiro & 28697 & $\mathrm{~N}$ \\
\hline Mikania glomerata Spreng. & guaco & 28702 & $\mathrm{C}$ \\
\hline Porophyllum ruderale (Jacq.) Cass. & arnica-cravo-de-urubu, arnica, arnica-do-campo & 28615 & $\mathrm{~N}$ \\
\hline Pterocaulon polystachyum DC. & calção-de-velho, quitoco & 28693 & $\mathrm{~N}$ \\
\hline Solidago chilensis Meyen & arnica, arnica caseira & 28574 & $\mathrm{C}$ \\
\hline Tagetes patula $\mathrm{L}$. & cravo-de-defunto & 28658 & $\mathrm{C}$ \\
\hline Vernonia condensata Baker & firgatil, estomalina & 28685 & $\mathrm{C}$ \\
\hline Vernonia scabra Pers. & assapeixe & 28597 & $\mathrm{~N}$ \\
\hline \multicolumn{4}{|l|}{ BEGONIACEAE } \\
\hline Begonia sp. & begônia & 28729 & $\mathrm{C}$ \\
\hline \multicolumn{4}{|l|}{ BIGNONIACEAE } \\
\hline Jacaranda cuspidifolia Mart. & carobinha-do-cerrado & 28621 & $\mathrm{~N}$ \\
\hline Tabebuia impetiginosa (Mart. ex DC.) Standl. & ipê-roxo & 28570 & $\mathrm{~N}$ \\
\hline $\begin{array}{l}\text { Tabebuia aurea (Silva Manso) Benth. \& Hook. f. } \\
\text { ex S. Moore }\end{array}$ & paratudo & - & $\mathrm{N}$ \\
\hline \multicolumn{4}{|l|}{ BIXACEAE } \\
\hline Bixa orellana $\mathrm{L}$. & colorau & 28585 & $\mathrm{C}$ \\
\hline Cochlospermum regium (Schrank) Pilg. & algodãozinho & 28592 & $\mathrm{~N}$ \\
\hline \multicolumn{4}{|l|}{ BORAGINACEAE } \\
\hline Heliotropium indicum $\mathrm{L}$. & crista-de-galo & 28723 & $\mathrm{~N}$ \\
\hline \multicolumn{4}{|l|}{ BRASSICACEAE } \\
\hline Brassica oleracea $\mathrm{L}$. & couve & 28714 & $\mathrm{C}$ \\
\hline \multicolumn{4}{|l|}{ BROMELIACEAAE } \\
\hline Ananas comosus (L.) Merr. & abacaxi & - & $\mathrm{C}$ \\
\hline Bromelia balansae $\mathrm{Mez}$ & caraguatá & 28673 & $\mathrm{~N}$ \\
\hline \multicolumn{4}{|l|}{ BURSERACEAE } \\
\hline Commiphora leptophloeos (Mart.) J.B. Gillett & emburana & 28665 & $\mathrm{~N}$ \\
\hline Protium heptaphyllum (Aubl.) Marchand & amescla & 28687 & $\mathrm{~N}$ \\
\hline \multicolumn{4}{|l|}{ CACTACEAE } \\
\hline Cereus sp. & mandacaru & - & $\mathrm{C}$ \\
\hline
\end{tabular}


Tabela 1. Continuação.

\begin{tabular}{|c|c|c|c|}
\hline Familia/Espécie & Nome Popular & Ref & C ou N \\
\hline \multicolumn{4}{|l|}{ CANNABACEAE } \\
\hline Celtis pubescens Spreng. & taleiro, juá, esporão, grão-de-galo & 28625 & $\mathrm{~N}$ \\
\hline \multicolumn{4}{|l|}{ CARICACEAE } \\
\hline Carica papaya $\mathrm{L}$. & mamão & - & $\mathrm{C}$ \\
\hline \multicolumn{4}{|l|}{ CARYOCARACEAE } \\
\hline Caryocar brasiliense Cambess. & pequi & 28603 & $\mathrm{~N}$ \\
\hline \multicolumn{4}{|l|}{ CELASTRACEAE } \\
\hline Maytenus ilicifolia (Schrad.) Planch. & cancorosa & 28600 & $\mathrm{~N}$ \\
\hline \multicolumn{4}{|l|}{ COMBRETACEAE } \\
\hline Terminalia argentea Mart. & capitão & 28718 & $\mathrm{~N}$ \\
\hline \multicolumn{4}{|l|}{ CONVOLVULACEAE } \\
\hline Cuscuta racemosa Mart. & cabelo-de-anjo & 28713 & $\mathrm{C}$ \\
\hline Ipomoea batatas (L.) Lam. & batata-doce & 28712 & $\mathrm{C}$ \\
\hline Ipomoea sp. & jetirana/corda-de-viola & 28671 & $\mathrm{~N}$ \\
\hline \multicolumn{4}{|l|}{ COSTACEAE } \\
\hline Costus arabicus $\mathrm{L}$. & cana-do-brejo, cana-de- macaco & 28619 & $\mathrm{~N}$ \\
\hline \multicolumn{4}{|l|}{ CRASSULACEAE } \\
\hline Kalanchoe brasiliensis Cambess. & folha-santa, fortuna & 28576 & $\mathrm{C}$ \\
\hline \multicolumn{4}{|l|}{ CUCURBITACEAE } \\
\hline Cucumis anguria $\mathrm{L}$. & maxixe & 28686 & $\mathrm{C}$ \\
\hline Cucurbita sp. & abóbora & - & $\mathrm{C}$ \\
\hline Luffa cylindrica M. Roem. & bucha-caipira & 28655 & $\mathrm{~N}$ \\
\hline Momordica charantia $\mathrm{L}$. & melão-de-são-caetano & 28656 & $\mathrm{~N}$ \\
\hline Sechium edule (Jacq.) Sw. & chuchu & - & $\mathrm{C}$ \\
\hline Siolmatra brasiliensis (Cogn.) Baill. & taiuiá & 28730 & $\mathrm{C}$ \\
\hline \multicolumn{4}{|l|}{ CYPERACEAE } \\
\hline Cyperus corymbosus Rottb. & junco & 28731 & $\mathrm{C}$ \\
\hline \multicolumn{4}{|l|}{ DILLENIACEAE } \\
\hline Curatella americana $\mathrm{L}$. & lixeira & 28666 & $\mathrm{~N}$ \\
\hline Davilla elliptica A. St.-Hil. & lixeirinha & 28667 & $\mathrm{~N}$ \\
\hline \multicolumn{4}{|l|}{ EQUISETACEAE } \\
\hline Equisetum giganteum $L$. & cavalinha & 28635 & $\mathrm{~N}$ \\
\hline \multicolumn{4}{|l|}{ EUPHORBIACEAE } \\
\hline Croton urucurana Baill. & sangra-d’água & 28650 & $\mathrm{~N}$ \\
\hline Croton sp. & velame & 28607 & $\mathrm{~N}$ \\
\hline Jatropha curcas L. & pinhão & 28711 & $\mathrm{C}$ \\
\hline Jatropha elliptica (Pohl) Oken & vick, vaporube, jalapa, carijó & 28632 & $\mathrm{~N}$ \\
\hline Jatropha gossypiifolia L. & pinhão-roxo & - & $\mathrm{C}$ \\
\hline Manihot esculenta Crantz & mandioca & 28710 & $\mathrm{C}$ \\
\hline Ricinus communis $\mathrm{L}$. & mamona & 28733 & $\mathrm{C}$ \\
\hline \multicolumn{4}{|l|}{ FABACEAE } \\
\hline Acosmium subelegans (Mohlenbr.) Yakovlev & genciana & 28682 & $\mathrm{~N}$ \\
\hline Amburana cearensis (Allemão)A.C.Sm. & emburana & 28738 & $\mathrm{~N}$ \\
\hline Anadenanthera peregrina (L.) Speg. & angico & 28688 & $\mathrm{~N}$ \\
\hline
\end{tabular}


Tabela 1. Continuação.

\begin{tabular}{|c|c|c|c|}
\hline Familia/Espécie & Nome Popular & Ref & $\mathrm{C}$ ou $\mathrm{N}$ \\
\hline Bauhinia mollis (Bong.) D. Dietr. & pata-de-vaca & 28616 & $\mathrm{~N}$ \\
\hline Cajanus cajan (L.) Huth & feijão-guandu & 28571 & $\mathrm{C}$ \\
\hline Copaifera langsdorffii Desf. & pau-dóleo, copaíba & - & $\mathrm{N}$ \\
\hline Crotalaria sp. & saco-de-bode & 28644 & $\mathrm{~N}$ \\
\hline Dimorphandra mollis (Bong.) D. Dietr. & fava-de-anta & 28639 & $\mathrm{~N}$ \\
\hline Dioclea grandiflora Mart. ex Benth. & coronha-de-boi & 28734 & $\mathrm{C}$ \\
\hline Dipteryx alata Vogel & cumbaru & 28620 & $\mathrm{~N}$ \\
\hline Hymenaea courbaril L. & jatobá & 28648 & $\mathrm{~N}$ \\
\hline Hymenaea martiana Hayne & jatobá & 28618 & $\mathrm{~N}$ \\
\hline Indigofera hirsuta $\mathrm{L}$. & anil & 28626 & $\mathrm{~N}$ \\
\hline Inga vera Willd. & ingá & 28700 & $\mathrm{~N}$ \\
\hline Mimosa setosa Benth. & malícia & 28628 & $\mathrm{~N}$ \\
\hline Mimosa sp. & malícia-braba & 28631 & $\mathrm{~N}$ \\
\hline Pterodon pubescens (Benth.) Benth. & sucupira & 28683 & $\mathrm{~N}$ \\
\hline Senna alata (L.) Roxb. & baraio, mata-pasto & 28586 & $\mathrm{~N}$ \\
\hline Senna occidentalis (L.) Link & fedegoso & 28563 & $\mathrm{~N}$ \\
\hline Stryphnodendron obovatum Benth. & barbatimão & 28617 & $\mathrm{~N}$ \\
\hline Tamarindus indica $\mathrm{L}$. & tamarindo & 28572 & $\mathrm{C}$ \\
\hline Vatairea macrocarpa (Benth.) Ducke & maleitoso & 28741 & $\mathrm{~N}$ \\
\hline sp.1 & mussambê & 28736 & $\mathrm{~N}$ \\
\hline \multicolumn{4}{|l|}{ IRIDACEAE } \\
\hline Eleutherine bulbosa (Mill.) Urb. & coqueirinho-do-campo/cebolinha & 28659 & $\mathrm{~N}$ \\
\hline Sisyrinchium alatum Hook. & capim-lanceta & 28661 & $\mathrm{~N}$ \\
\hline Trimezia juncifolia Klatt & ruibarbo & 28674 & $\mathrm{~N}$ \\
\hline \multicolumn{4}{|l|}{ LAMIACEAE } \\
\hline Leonotis nepetifolia (L.) R. Br. & cordão-de-frade & 28709 & $\mathrm{~N}$ \\
\hline Mentha pulegium $\mathrm{L}$. & poejo & 28568 & $\mathrm{C}$ \\
\hline Mentha sp. & hortelã-de-folha-miúda, hortelã-miúda, hortelã-menta & - & $\mathrm{C}$ \\
\hline Ocimum basilicum $\mathrm{L}$. & manjericão & 28582 & $\mathrm{C}$ \\
\hline Ocimum gratissimum $\mathrm{L}$. & alfavaca, alfavaca-cravo & 28590 & $\mathrm{C}$ \\
\hline Origanum vulgare $\mathrm{L}$. & manjerona & 28569 & $\mathrm{C}$ \\
\hline Plectranthus amboinicus (Lour.) Spreng. & hortelã-costela-de-vaca, hortelã-folha-grande, hortelã-gorda & 28583 & $\mathrm{C}$ \\
\hline Plectranthus barbatus Andrews & boldo-do-chile, boldo & 28578 & $\mathrm{C}$ \\
\hline Rosmarinus officinalis $\mathrm{L}$. & alecrim, poleo & 28701 & $\mathrm{C}$ \\
\hline \multicolumn{4}{|l|}{ LAURACEAE } \\
\hline Persea americana Mill. & abacate & 28708 & $\mathrm{C}$ \\
\hline \multicolumn{4}{|l|}{ LOGANIACEAE } \\
\hline Strychnos pseudoquina St. Hil. & quina-do-cerrado, quinão, quina-amarela & 28740 & $\mathrm{~N}$ \\
\hline \multicolumn{4}{|l|}{ LYTHRACEAE } \\
\hline Lafoensia pacari A. St.-Hil. & didal, cassete-de-burro, didaleira & 28719 & $\mathrm{~N}$ \\
\hline Punica granatum L. & romã & 28567 & $\mathrm{C}$ \\
\hline \multicolumn{4}{|l|}{ MALPIGHIACEAE } \\
\hline Heteropterys aphrodisiaca O. Mach. & nó-de-cachorro & 28704 & $\mathrm{~N}$ \\
\hline Malpighia glabra L. & acerola & - & $\mathrm{C}$ \\
\hline Peixotoa sp. & nó-de-cadela & 28705 & $\mathrm{~N}$ \\
\hline
\end{tabular}


Tabela 1. Continuação.

\begin{tabular}{|c|c|c|c|}
\hline Familia/Espécie & Nome Popular & Ref & C ou $\mathrm{N}$ \\
\hline \multicolumn{4}{|l|}{ MALVACEAE } \\
\hline Abelmoschus esculentus (L.) Moench & quiabo & - & $\mathrm{C}$ \\
\hline Guazuma ulmifolia Lam. & chico-magro & - & $\mathrm{N}$ \\
\hline Luehea paniculata Mart. & açoita-cavalo & 28646 & $\mathrm{~N}$ \\
\hline Physalis sp. & papo-de-peru & 28743 & $\mathrm{~N}$ \\
\hline Sida rhombifolia L. & guaxumba-miuda, guaxumba, malva-guaxumba & 28612 & $\mathrm{~N}$ \\
\hline Sida sp. & guaxumba & 28672 & $\mathrm{~N}$ \\
\hline Waltheria indica $\mathrm{L}$. & malva-do-reino-branca, malva-branca & 28640 & $\mathrm{~N}$ \\
\hline \multicolumn{4}{|l|}{ MELIACEAE } \\
\hline Cedrela fissilis Vell. & cedro & - & $\mathrm{C}$ \\
\hline Melia azedarach $\mathrm{L}$. & santa-bárbara, cinamomo, paraíso & 28735 & $\mathrm{C}$ \\
\hline \multicolumn{4}{|l|}{ MORACEAE } \\
\hline Brosimum gaudichaudii Trécul & mamica-de-cadela & 28608 & $\mathrm{~N}$ \\
\hline Dorstenia brasiliensis Lam. & carapiá & 28598 & $\mathrm{~N}$ \\
\hline Maclura tinctoria (L.) D. Don ex Steud. & amoreira & 28677 & $\mathrm{~N}$ \\
\hline \multicolumn{4}{|l|}{ MYRTACEAE } \\
\hline Campomanesia sp. & guavira & 28587 & $\mathrm{~N}$ \\
\hline Eucalyptus citriodora Hook. & eucalipto & 28577 & $\mathrm{C}$ \\
\hline Eugenia pitanga (O. Berg) Kiaersk. & pitanga-do-campo & 28706 & $\mathrm{~N}$ \\
\hline Eugenia uniflora $\mathrm{L}$. & pitanga & - & $\mathrm{C}$ \\
\hline Psidium sp. & araçá & 28647 & $\mathrm{~N}$ \\
\hline Psidium guajava $\mathrm{L}$. & goiaba & 28645 & $\mathrm{C}$ \\
\hline Syzygium cumini (L.) Skeels & jamelão & 28724 & $\mathrm{C}$ \\
\hline \multicolumn{4}{|l|}{ NYCTAGINACEAE } \\
\hline Boerhavia diffusa $\mathrm{L}$. & pega-pinto, erva-tostão, amarra-pinto & 28636 & $\mathrm{~N}$ \\
\hline Mirabilis jalapa L. & maravilha & 28652 & $\mathrm{C}$ \\
\hline \multicolumn{4}{|l|}{ OXALIDACEAE } \\
\hline Averrhoa carambola $\mathrm{L}$. & carambola & 28649 & $\mathrm{C}$ \\
\hline \multicolumn{4}{|l|}{ PASSIFLORACEAE } \\
\hline Passiflora & maracujá & 28651 & $\mathrm{C}$ \\
\hline \multicolumn{4}{|l|}{ PEDALIACEAE } \\
\hline Sesamum orientale $\mathrm{L}$. & gergelim & 28692 & $\mathrm{C}$ \\
\hline \multicolumn{4}{|l|}{ PHYLLANTHACEAE } \\
\hline Phyllanthus niruri L. & quebra-pedra & 28611 & $\mathrm{~N}$ \\
\hline \multicolumn{4}{|l|}{ PHYTOLACCACEAE } \\
\hline Petiveria alliacea $\mathrm{L}$. & guiné & 28609 & $\mathrm{~N}$ \\
\hline \multicolumn{4}{|l|}{ PIPERACEAE } \\
\hline Piper umbellatum $\mathrm{L}$. & pariparoba & 28643 & $\mathrm{~N}$ \\
\hline Piper sp. & jaborandi & 28624 & $\mathrm{~N}$ \\
\hline \multicolumn{4}{|l|}{ PLANTAGINACEAE } \\
\hline Plantago major $L$. & tansagem & 28602 & $\mathrm{C}$ \\
\hline Scoparia dulcis L. & vassourinha-do-campo & 28654 & $\mathrm{~N}$ \\
\hline \multicolumn{4}{|l|}{ POACEAE } \\
\hline Coix lacryma-jobi $\mathrm{L}$. & lágrima-de-nossa-senhora & - & $\mathrm{N}$ \\
\hline
\end{tabular}


Tabela 1. Continuação.

\begin{tabular}{|c|c|c|c|}
\hline Familia/Espécie & Nome Popular & Ref & C ou N \\
\hline Cymbopogon citratus (DC.) Stapf & capim-santo, capim-cidreira & 28641 & $\mathrm{C}$ \\
\hline Digitaria insularis (L.) Fedde & capim-amargoso & 28679 & $\mathrm{~N}$ \\
\hline Eleusine indica (L.) Gaertn. & pé-de-galinha & 28633 & $\mathrm{~N}$ \\
\hline Guadua paniculata Munro & taboca & 28696 & $\mathrm{~N}$ \\
\hline Melinis minutiflora P. Beauv. & capim-gordura & 28680 & $\mathrm{~N}$ \\
\hline Saccharum officinarum $\mathrm{L}$. & cana & - & $\mathrm{C}$ \\
\hline $\begin{array}{l}\text { Sorghum bicolor var. technicum (Körn.) Stapf } \\
\text { ex Holland }\end{array}$ & vassoura & 28715 & $\mathrm{C}$ \\
\hline Zea mays L. & milho & - & $\mathrm{C}$ \\
\hline \multicolumn{4}{|l|}{ POLYGALACEAE } \\
\hline Bredemeyera floribunda Willd. & pau-gemada & 28676 & $\mathrm{~N}$ \\
\hline \multicolumn{4}{|l|}{ POLYGONACEAE } \\
\hline Polygonum acuminatum Kunth & erva-de-bicho & 28637 & $\mathrm{~N}$ \\
\hline \multicolumn{4}{|l|}{ PORTULACACEAE } \\
\hline Portulaca oleracea $\mathrm{L}$. & berduega & 28601 & $\mathrm{C}$ \\
\hline \multicolumn{4}{|l|}{ RHAMNACEAE } \\
\hline Ziziphus joazeiro Mart. & juá-do-norte & 28707 & $\mathrm{C}$ \\
\hline \multicolumn{4}{|l|}{ ROSACEAE } \\
\hline Morus nigra L. & amora & 28605 & $\mathrm{C}$ \\
\hline \multicolumn{4}{|l|}{ RUBIACEAE } \\
\hline Alibertia edulis (Rich.) A. Rich. ex DC. & marmelo & 28689 & $\mathrm{~N}$ \\
\hline Chiococca alba (L.) Hitchc. & cainca & 28725 & $\mathrm{~N}$ \\
\hline Chomelia sp. & gelol & 28623 & $\mathrm{~N}$ \\
\hline Coffea arabica $\mathrm{L}$. & café & 28691 & $\mathrm{C}$ \\
\hline Palicourea coriacea (Cham.) K. Schum. & douradinha-do-campo, douradinha & 28703 & $\mathrm{~N}$ \\
\hline \multicolumn{4}{|l|}{ RUTACEAE } \\
\hline Ruta graveolens $\mathrm{L}$. & arruda & 28694 & $\mathrm{C}$ \\
\hline Citrus aurantifolia (Christm.) Swingle & laranja-lima, lima & - & $\mathrm{C}$ \\
\hline Citrus limon (L.) Burm. f. & limão & 28594 & $\mathrm{C}$ \\
\hline Citrus sp. & laranja & 28630 & $\mathrm{C}$ \\
\hline Zanthoxylum rhoifolium Lam. & mamica-de-porca & 28690 & $\mathrm{~N}$ \\
\hline \multicolumn{4}{|l|}{ SALICACEAE } \\
\hline Casearia gossypiosperma Briq. & espeteiro & 28675 & $\mathrm{~N}$ \\
\hline \multicolumn{4}{|l|}{ SMILACACEAE } \\
\hline Smilax sp. & japecanga & 28653 & $\mathrm{~N}$ \\
\hline \multicolumn{4}{|l|}{ SOLANACEAE } \\
\hline Capsicum frutescens $\mathrm{L}$. & pimenta & 28716 & $\mathrm{C}$ \\
\hline Solanum americanum Mill. & maria-preta & 28722 & $\mathrm{~N}$ \\
\hline Solanum paniculatum L. & jurubeba & 28595 & $\mathrm{C}$ \\
\hline Solanum sp. & juá & 28657 & $\mathrm{~N}$ \\
\hline \multicolumn{4}{|l|}{ VERBENACEAE } \\
\hline Aloysia sp. & alecrim-do-chile, alcanflor & 28580 & $\mathrm{C}$ \\
\hline Lantana camara L. & camará, chumbinho & 28627 & $\mathrm{~N}$ \\
\hline Lippia alba (Mill.) N.E. Br. & cidreira-de-folha-redonda, sálvia, erva-cidreira & 28579 & $\mathrm{C}$ \\
\hline Stachytarpheta cayennensis (Rich.) Vahl & gervão ou erva-de-grilo & 28564 & $\mathrm{~N}$ \\
\hline
\end{tabular}


Tabela 1. Continuação.

\begin{tabular}{|c|c|c|c|}
\hline Familia/Espécie & Nome Popular & Ref & C ou N \\
\hline \multicolumn{4}{|l|}{ VITACEAE } \\
\hline Vitis vinifera $\mathrm{L}$. & uva & 28604 & $\mathrm{C}$ \\
\hline \multicolumn{4}{|l|}{ VOCHYSIACEAE } \\
\hline Vochysia rufa Mart. & pau-doce & 28737 & $\mathrm{~N}$ \\
\hline \multicolumn{4}{|l|}{ ZINGIBERACEAE } \\
\hline Alpinia zerumbet (Pers.) B.L. Burtt \& R.M. Sm. & noz-moscada & 28717 & $\mathrm{C}$ \\
\hline Curcuma longa $\mathrm{L}$. & açafrão & 28606 & $\mathrm{C}$ \\
\hline Zingiber officinale Roscoe & gengibre & - & $\mathrm{C}$ \\
\hline \multicolumn{4}{|l|}{ INDETERMINADA } \\
\hline sp. 2 & quina-do-campo & 28634 & $\mathrm{~N}$ \\
\hline sp. 3 & catinga-de-urubu & 28742 & $\mathrm{~N}$ \\
\hline sp.4 & catinga-de-porco & 28739 & $\mathrm{~N}$ \\
\hline sp. 5 & guaraná & 28720 & $\mathrm{C}$ \\
\hline sp.6 & urtiga & 28699 & $\mathrm{~N}$ \\
\hline sp.7 & jõao-da-costa & 28744 & $\mathrm{~N}$ \\
\hline
\end{tabular}

Doenças do aparelho respiratório (gripe, tosse e resfriado) e geniturinário (Fig. 2) foram as mais citadas. Resultados semelhantes foram registrados na Amazônia (Amorozo \& Gély, 1988), na Mata Atlântica (Di Stasi et al. 2002), no Cerrado e Mata Atlântica (Pilla et al. 2006) e no Cerrado (Silva \& Proença 2008). O fato do aparelho geniturinário ter um grande número de citações pode ter sido influenciado pelo número de mulheres que fazem parte da amostra. Todas elas citaram pelo menos uma espécie utilizada para tratar doenças como problemas no útero, cólica, regular menstruação.

A diversidade de usos das espécies é alta $\left(H^{\prime}=5,03\right)$ e é próxima aos valores encontrados por Amorozo (2002) em áreas de Cerrado e reflete a disponibilidade dos recursos vegetais nativos e cultivados e a familiaridade da população com estes recursos. Isso é confirmado também pelo alto valor de equitabilidade $(e=0,94)$, mostrando que o conhecimento sobre uso de plantas tem distribuição relativamente uniforme entre os indivíduos do estudo. De acordo com Begossi (1996), índices de diversidade altos sugerem que a população utiliza uma grande parcela da diversidade local e espera-se que quanto maior a diversidade florística local, maior a diversidade de espécies usadas.

A riqueza de espécies (209) também pode ser considerada alta, sendo maior que a riqueza de espécies de plantas medicinais encontradas em estudos em comunidades tradicionais (Schardong \& Cervi 2000) e indígenas (Bueno et al. 2005) no Mato Grosso do Sul. É possível que esse resultado tenha sido influenciado pela idade dos entrevistados, cuja faixa etária variou entre 35 e 89 anos (média 54 anos). Segundo Phillips \& Gentry (1993), pessoas idosas conhecem um maior número de plantas medicinais. A facilidade em obter os recursos próximos à sua casa para tratar as doenças e a dificuldade em ir até a cidade consultar um médico e adquirir remédios industrializados contribui para o aumento no consumo de remédios caseiros e explica a grande riqueza de espécies na comunidade. Além disso, os entrevistados se assemelham a um dos grupos estudados por Oliveira et al. (2010) numa comunidade urbana do nordeste brasileiro, pelo fato de terem recebido treinamento, ou seja participarem de cursos e reuniões sobre plantas medicinais e serem considerados especialistas. De acordo com esses autores, o treinamento propicia melhor aprendizado sobre a diversidade de plantas em relação a não especialistas.

Das 209 espécies citadas, cerca de 57\% são nativas e inclusas na lista de plantas do Cerrado de Mendonça et al. (1998) e/ou Guarim Neto \& Morais (2003). O restante, cerca de $43 \%$, são cultivadas próximas das casas nas áreas manejadas como quintais e roças. Foram incluídas espécies nativas citadas nestas listas, mas que eram cultivadas pelos moradores. Bortolotto (2007) comenta que as populações humanas selecionam plantas para sua subsistência e diversificam a paisagem introduzindo espécies oriundas de outros locais e destaca que, assim como neste estudo, nas áreas manejadas (onde se incluem as roças e quintais) predominam espécies introduzidas e cultivadas. Bennett \& Prance (2000) chamam a atenção para a importância das espécies introduzidas na farmacopéia vegetal de povos índigenas e mestiços do Norte da América do Sul, onde muitas destas plantas foram introduzidas na época da conquista européia, para fins alimentares e ornamentais, e seu uso acabou sendo estendido à cura de enfermidades. Houve dificuldade em separar esses grupos em função das divergências quanto aos dados encontrados. Segundo Lévi-Strauss (1987), nem sempre é fácil distinguir plantas silvestres das cultivadas, uma vez 


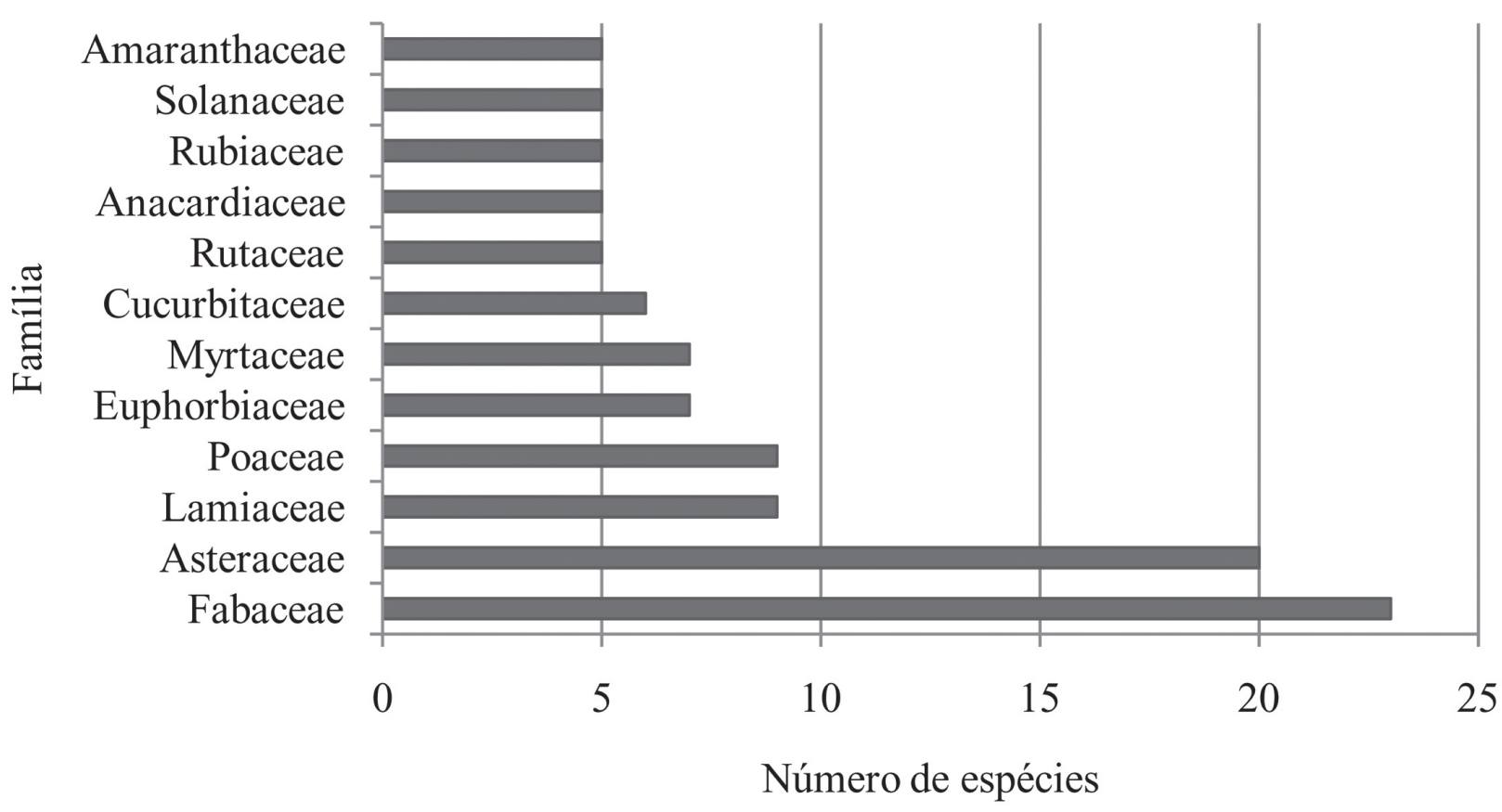

Figura 1. Famílias mais representativas das espécies medicinais usadas pelos moradores do Assentamento Monjolinho, Anastácio, MS.

que existem estágios intermediários. As espécies ruderais encontradas em áreas de Cerrado também foram inclusas na categoria nativa, pois segundo Mendonça et al. (1998), elas são plantas autóctones na região.

$\mathrm{Na}$ amostra, foi verificada em todos os lotes a presença de um quintal diferenciado do restante dos lotes do assentamento, apresentando plantas utilizadas pelos moradores como alimentícias e ornamentais, além das medicinais. A afinidade pelas plantas é uma característica dos entrevistados, que utilizam espécies nativas encontradas nas áreas preservadas dos seus lotes, as que eles toleram (presentes no pasto e na roça), as que nascem espontaneamente ao redor das suas casas. $\mathrm{O}$ assentamento Monjolinho tem uma ocupação recente (cerca de 20 anos) e os moradores são oriundos do Nordeste (11\%), do Sudeste (28\%), do Sul (21\%) e $28 \%$ são de Mato Grosso do Sul. Isso mostra uma heterogeneidade da população (em relação à cultura dos diversos locais de origem) e o que os une é a identidade com a terra, fazendo com que acumulem informações, através da incorporação de novos conhecimentos sobre as plantas do local.

Os moradores do assentamento utilizam as plantas medicinais, seja para preparo de um simples chá para tratar enfermidades cotidianas, ou para tratamentos longos como os feitos com garrafadas ou xaropes. O modo de administração mais citado foi por via oral (84\%), principalmente sob forma de chás (infusão ou decocção $77 \%$ ), o que também foi verificados em estudos em outras comunidades rurais como em Pinto et. al. (2006) e Santos et al. (2008). Outras formas de utilização foram: tintura
$(7,8 \%)$ e xarope $(6 \%)$; banhos ou outro tipo de aplicação externa $(8,3 \%)$. Verificou-se que eles adicionam algumas espécies no preparo do tereré e chimarrão, bebidas popularmente conhecidas no Brasil, muito consumidas na região. Utilizam a combinação de várias plantas na preparação de chás e garrafadas. Segundo Lévi-Strauss (1987), os primeiros viajantes que chegaram ao Brasil ficaram surpresos com o número de plantas medicinais conhecidas pelos índios e estes usavam remédios simples, empregando apenas uma planta de cada vez, ao contrário dos europeus, que confiavam em combinações semimágicas de ervas medicinais. Isto mostra diferentes influências na aquisição de conhecimentoQuando foi perguntado com quem aprendeu os usos das plantas medicinais, 37\% dos entrevistados responderam que foi entre amigos/as ou através de cursos (17\%), que pode ser considerada uma forma de transmissão horizontal. Eyssartier et al. (2008) citam o intercâmbio e práticas extra-familiares durante a vida adulta como sendo exemplo de fonte de informação e conhecimento. O relacionamento social permite a transmissão do conhecimento é outra das prováveis causas da grande riqueza de espécies (além da idade dos entrevistados) e do grande conhecimento a respeito dos usos medicinal dessas espécies pode ter ligação com o que foi relatado pelos moradores. Na formação do assentamento, enquanto ainda estavam acampados às margens do Córrego Engano, a Pastoral da Terra, a cada 15 dias, ministrava cursos para as pessoas com maiores aptidões com as plantas medicinais, para que essas repassassem ao demais assentados. Isso aconteceu por 1 ano até a demarcação da terra. Na região Nordeste, as Pastorais 
Tabela 2. Nome científico, uso principal e porcentagem de concordância quanto ao(s) uso(s) principal (is) (espécies citadas por cinco ou mais informantes). ICUE - $\mathrm{n}^{\circ}$ de informantes citando uso da espécie; ICUP - $\mathrm{n}^{\circ}$ de informantes citando uso principal; CUP - índice de concordância de uso; FC - fator de correção; CUPc CUP corrigida no assentamento Monjolinho, Anastácio - MS.

\begin{tabular}{|c|c|c|c|c|c|c|}
\hline Nome Científico & Uso principal & ICUE & ICUP & CUP & FC & CUPc \\
\hline Stryphnodendron obovatum Benth. & Cicatrizante feridas & 23 & 21 & 91,3 & 1 & 82,6 \\
\hline Maytenus ilicifolia (Schrad.) Planch. & Depurativo do sangue & 18 & 16 & 88,8 & 0,78 & 69,2 \\
\hline Morus nigra L. & Pressão & 21 & 18 & 85,7 & 0,91 & 77,9 \\
\hline Hymenaea spp. & Tosse, resfriados e bronquite & 23 & 19 & 82,6 & 1 & 82,6 \\
\hline Hancornia speciosa Gomez & Coluna & 18 & 13 & 72,2 & 0,78 & 56,3 \\
\hline Chenopodium ambrosioides L. & Vermes & 20 & 14 & 70 & 0,86 & 60,2 \\
\hline Senna occidentalis (L.) Link & Gripe forte & 16 & 11 & 68,7 & 0,69 & 47,4 \\
\hline Achyrocline satureioides (Lam.) DC. & Dor de barriga, má digestão & 15 & 10 & 66,6 & 0,65 & 43,2 \\
\hline Ruta graveolens $\mathrm{L}$. & Cólicas menstruais e pós parto & 13 & 8 & 61,5 & 0,56 & 34,4 \\
\hline Lippia alba (Mill.) N.E. Br. & Gripe, tosse & 13 & 7 & 53,8 & 0,56 & 30,1 \\
\hline Pterodon pubescens (Benth.) Benth. & Garganta & 17 & 9 & 52,9 & 0,73 & 38,6 \\
\hline Boerhavia diffusa L. & Urina, rins & 13 & 6 & 46,1 & 0,56 & 25,8 \\
\hline Porophyllum ruderale (Jacq.) Cass. & Machucados & 13 & 6 & 46,1 & 0,56 & 25,8 \\
\hline Stachytarpheta cayennensis (Rich.) Vahl & Cicatrizante feridas & 14 & 6 & 42,8 & 0,6 & 25,6 \\
\hline Lafoensia pacari A. St.-Hil. & Cicatrizante feridas & 15 & 6 & 40 & 0,65 & 26 \\
\hline Solanum sp. & Furúnculo & 13 & 5 & 38,4 & 0,56 & 21,5 \\
\hline Tabebuia impetiginosa (Mart. ex DC.) Standl. & Problemas no útero & 14 & 5 & 35,7 & 0,6 & 21,4 \\
\hline
\end{tabular}

da Saúde e da Criança incentivam a troca de experiências entre seus integrantes, troca de mudas, cultivo em hortas caseiras ou comunitárias, organizam cursos para seus agentes, buscam informações sobre o cultivo, coleta, secagem e preparo de medicamentos simples. Segundo Scheffer et al. (1999) isto vem proporcionando alívio às comunidades mais destituídas de assistência médica.

Há de se acrescentar ainda o papel da família na transmissão do conhecimento, que foi citada por $39 \%$ dos entrevistados, evidenciando a transmissão vertical entre os membros da família. Lozada et al. (2006) encontraram esse modo de transmissão para uma comunidade rural na Patagônia. Cerca de 60\% dos entrevistados é oriunda de diversas regiões do país e trazem com eles uma bagagem cultural muito grande, repassada de geração a geração pelos pais, avós ou outra figura familiar. A figura materna foi a mais representativa (74\%), seguida por avós (21\%). Se considerarmos que a ocupação é recente, e que os moradores tiveram diversas oportunidades de aprender com os cursos oferecidos, pode-se considerar que a família ainda pode ser considerada como importante na transmissão do conhecimento para a comunidade estudada.

A transmissão do conhecimento pode ser repassada para os filhos, irmãos, vizinhos e conhecidos, verbalmente ou acompanhando experiências práticas. Segundo Lozada et al. (2006), as pessoas aprendem sobre o uso de plantas: "fazendo", através da observação participante, e através da partilha das atividades. O uso de linguagem escrita no repasse dos conhecimentos é muito pequeno. Entre as pessoas entrevistadas, o nível de alfabetização é baixo, não passando das séries iniciais do Ensino Fundamental, o que dificulta a manutenção e repasse das informações através da escrita. Mesmo com baixa escolaridade, os entrevistados manifestaram seu interesse e aceitação pelo estudo etnobotânico no Assentamento e acharam importante o registro das informações para que o conhecimento não seja perdido e que ficasse registrado para as próximas gerações.

Apesar desse estudo mostrar a grande afinidade dos entrevistados em relação ás plantas medicinais e o grande conhecimento dos seus usos, foi observado, em alguns lotes, a presença de fornos para fabricação de carvão vegetal, que é impulsionado pelas indústrias siderúrgicas que estão se estabelecendo próximas ao local. Os moradores retiram as espécies vegetais nativas para a fabricação de carvão para ajudar a renda familiar, pois como foi mostrado, eles não têm uma alternativa de renda fora a criação de gado leiteiro e a aposentadoria. O conhecimento popular sobre o uso das espécies vegetais nativas para fins medicinais pode se constituir de uma alternativa sustentável para a conservação da flora do Cerrado, além de contribuir para o registro e preservação da cultura popular. As plantas citadas são usadas no tratamento de doenças na família e algumas pessoas relataram que vendem produtos medicinais na feira na cidade vizinha de Aquidauana. As espécies comercializadas são oriundas do Cerrado, tais como douradinha (Palicourea coriacea (Cham.) K. Schum.) jatobá (Hymenaea sp.), mangaba (Hancornia speciosa Gomez), sucupira (Pterodon pubescens (Benth.) Benth.), entre outras. Espécies nativas podem ser uma alternativa econômica para o aproveitamento sustentável da região (Almeida et al. 1998). Se considerarmos que já 


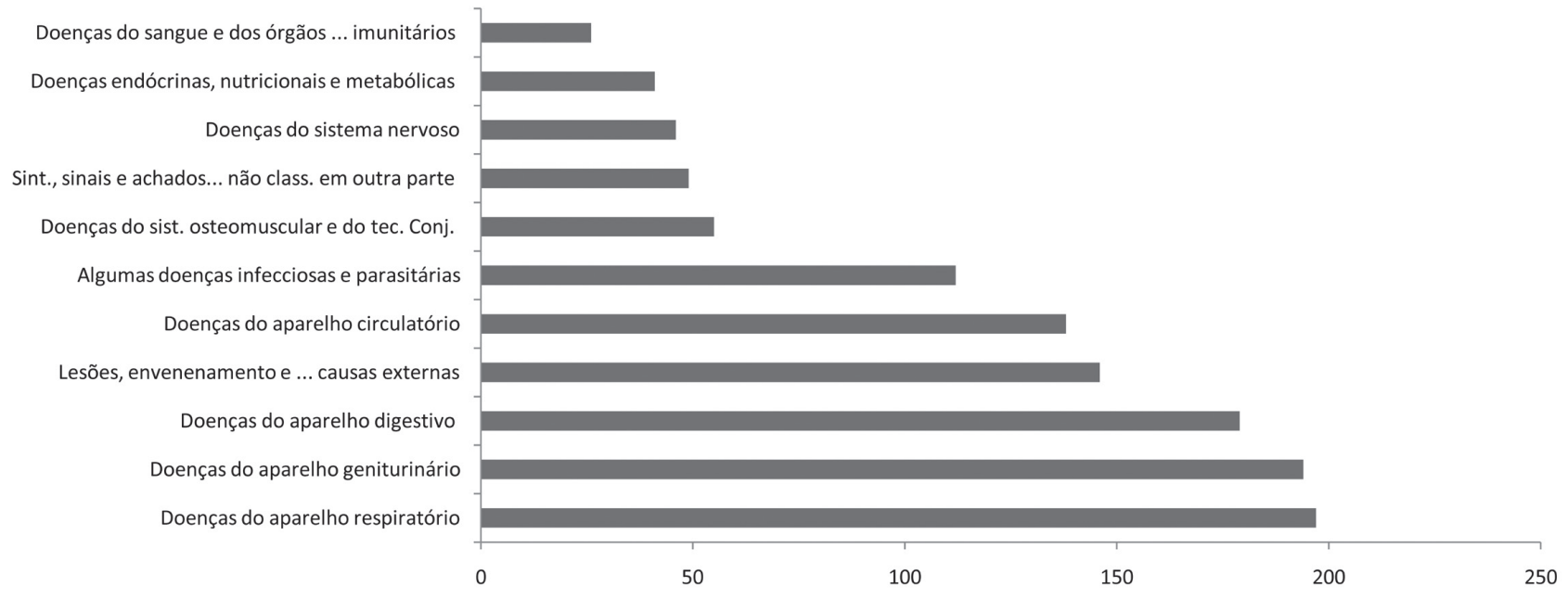

Figura 2. Número de citações de uso de plantas medicinais para cada categoria de doenças no Assentamento Monjolinho, no município de Anastácio, Nioaque - MS.

foram levantadas mais de 6.500 espécies plantas no Cerrado (Mendonça et al. 1998), destas mais de 500 são utilizadas como medicinais (Guarim Neto \& Moraes 2003), poderia ser aproveitado o conhecimento e as práticas de manejo dessas espécies medicinais populares conhecidas pelos entrevistados, que constituem um patrimônio de imenso valor, para a comercialização destes produtos. Estudos direcionados ao desenvolvimento dessa atividade podem ajudar a dinamizar o processo, pois os moradores que comercializam plantas relataram a falta de uma organização como sendo um dos empecilhos para que essa atividade ocorra de maneira mais funcional e rentável. Eles relatam que possuem potencial mercado consumidor. É importante que se estabeleçam linhas de ação voltadas para o desenvolvimento de técnicas de manejo sustentado, visando à utilização destas espécies vegetais pelo homem, aliada à manutenção do equilíbrio dos ecossistemas tropicais. No estudo, os moradores mostraram que utilizam práticas conservacionistas como a de não anelar os indivíduos quando coletam as cascas/entrecascas das plantas e se precisasse eles procuravam outro indivíduo para não esgotar o recurso.

O conhecimento adquirido através da percepção do ambiente local, as dificuldades passadas na formação do assentamento, o pequeno acesso a sistemas de saúde pública, a bagagem cultural, os cursos oferecidos e o seu cotidiano, onde incorporam novas informações, mostram que ao longo do tempo há um grande aproveitamento e conhecimento das espécies medicinais pela comunidade estudada.

\section{Agradecimentos}

À Coordenação de Aperfeiçoamento de Pessoal Nível Superior (CAPES), pela bolsa concedida à primeira autora; ao Programa de Pós-Graduação em Biologia Vegetal da UFMS; a Rede de Sementes do Pantanal em pessoa da professora Dra Edna Scremin Dias pela disponibilidade do uso da caminhonete; aos moradores do Assentamento Monjolinho e ao CEPPEC (Centro de Produção, Pesquisa e Capacitação do Cerrado).

\section{Referências bibliográficas}

Albuquerque, U.P. \& Andrade, L.H.C. 2002. Conhecimento botânico tradicional e conservação em uma área de caatinga no Estado de Pernambuco, Nordeste do Brasil. Acta Botanica Brasilica 16(3): 273-285.

Albuquerque, U.P. \& Lucena, R.F.P. 2004. Seleção e escolha dos informantes. Pp. 19-35. In: Albuquerque, U.P. \& Lucena, R.F.P. (Orgs.). Métodos e técnicas na pesquisa etnobotânica. Recife, Livro Rápido/NUPEEA.

Almeida, S.P.; Proença, C.E.B; Sano, S. M \& Ribeiro, J.F. 1998. Cerrado: espécies vegetais úteis. Planaltina, Embrapa-CPAC.

Alves, E.O.; Mota, J.H.; Soares, T.S.; Vieira, M.C. \& Silva, C.B. 2008. Levantamento etnobotânico e caracterização de plantas medicinais em fragmentos florestais de Dourados-MS. Ciência e Agrotecnologia 32(2): 651-658.

Amorozo, M.C.M. 1996. A abordagem Etnobotânica na Pesquisa de Plantas Medicinais. Pp. 47-67. In: Di-Stasi, L.C. Plantas Medicinais: Arte e Ciência: um guia de estudo interdisciplinar. São Paulo, Editora da Universidade Estadual Paulista.

Amorozo, M.C.M. 2002. Uso e diversidade de plantas medicinais em Santo Antonio do Leverger, MT, Brasil. Acta Botanica Brasilica 16(2): 189-203.

Amorozo, M.C.M. \& Gély, A. 1988. Uso de plantas medicinais por caboclos do Baixo Amazonas, Barcarena, PA, Brasil. Boletim do Museu Paranaense Emilio Goeldi, Série Botanica 4: 47-131.

Angiosperm Phylogeny Group. 2009. An update of the phylogeny group classification for the orders and families of flowering plants:APG III. Botanical Journal of the Linnean Society 161(2): 105-121.

Begossi, A. 1996. Use of Ecological Methods in Ethnobotany: Diversity Indices. Economic Botany 50(3): 280-289.

Begossi, A.; N. Hanazaki \& J. Tamashiro, 2002. Medicinal plants in the Atlantic Forest (Brazil): knowledge, use, and conservation. Human Ecology 30:281-299.

Bennett, B.C. \& Prance, G.T. 2000. Introduced plants in the indigenous pharmacopoeia of Northen South America. Economic Botany 54(1): 90-102. 
Bernard, H.R. 1995. Research Methods in Antropology. Qualitative and Quantitative Approachs. 2nd ed. Walnut Creek, Altamira Press.

Boesch, C. \& Tomasello, M. 1998. Chimpanzee and Human Cultures. Current Anthropology 39(5): 591- 604.

Bortolotto, I. M. 2007. Simpósio Plantas, Povos e Paisagens: Estudos de Casos no Pantanal Sul-Mato-Grossense. Pp. 223-227. In: Barbosa, L.M. \&, Júnior, N.A.S. (Org.). A botânica no Brasil: pesquisa, ensino e políticas públicas ambientais. Sociedade Botânica do Brasil, São Paulo.

Bueno, N.R.; Castilho, R.O.; Costa, R.B.; Pott A.; Pott, V.J.; Scheidt G.N. \& Batista, M.S. 2005. Medicinal plants used by the Kaiowá and Guarani indigenous populations in the Caarapó Reserve, Mato Grosso do Sul, Brazil. Acta Botanica Brasilica 19(1): 39-44.

Caniago, S. \& Siebert, S.F. 1998. Medicinal plant ecology, knowledge and conservation in Kalimantan, Indonésia. Economc Botany 52(3): 229-250

Cappellin, P. \& Castro, E.G. 1997. “Fazer, pensar e decidir: os papéis das mulheres nos assentamentos rurais. Algumas reflexões a partir de três estudos de casos". Raízes 15: 113-130.

Cavalli-Sforza, L.L.; Feldman, M.W.; Chen, K.H. \& Dornbusch, S.M. 1982. Theory and observation in cultural transmission. Science 218: 19-27

D’Aquino, T. 1998. Assentamento Como Nova Forma de Vida Rural: Espaço e Tempo no Assentamento Rural da Fazenda Reunidas - SP. Raízes 15: 47-61.

Di Stasi, L.C.; Oliveira, G.P.; Carvalhaes, M.A.; Queiroz-Junior, M.; Tien, O.S.; Kakinami, S.H. \& Reis, M.S. 2002. Medicinal plants popularly used in the Brazilian Tropical Atlantic Forest. Fitoterapia 73: 69-91.

Eyssartier, C.; Ladio, A.H. \& Lozada, M. 2008. Cultural Transmission of Traditional Knowledge in two populations of North-western Patagonia. Journal of Ethnobiology and Ethnomedicine 4: 25. 1-8.

Figueiredo, G. M.; Leitão-Filho, H. \& Begossi, A. 1993. Ethnobotany of Atlantic Forest Coastal Communities: diversity of plant uses in Gamboa (Itacuruça Island, Brazil). Human Ecology 2(4): 419-430.

Friedman, J.; Yaniv, Z.; Dafni, A. \& Palewitch, D. 1986. A preliminary classification of the healing potential of medicinal plants, based on a rational analysis of an ethnopharmacological field survey among bedouins in the negev desert, Israel. Journal of Ethnopharmacology 16: 275-287.

Guarim Neto, G.; Santana, S.R. \& Silva, J.V.B. 2000. Notas etnobotânicas de espécies de Sapindadeae Jussieu. Acta Botanica Brasilica 14(3): 327-334.

Guarim Neto, G. \& Morais, R.G. 2003. Recursos medicinais de espécies do Cerrado de Mato Grosso: Um estudo Bibliográfico. Acta Botanica Brasilica 17(4): 561-584.

INCRA - Instituto Nacional de Colonização e Reforma Agrária. 1990. Mapa da malha fundiária do Assentamento Monjolinho. Coordenadoria de Cartografia. P.A. Assentamento Monjolinho. Campo Grande, INCRA.

Kainer, K.A. \& M.L. Duryea. 1992. Tapping women's knowledge: Plant resource use in extractive reserves, Acre, Brazil. Economic Botany 46: 408-425.

Lévi-Strauss, C. 1987. "O uso das plantas silvestres da América do Sul tropical”. Pp. 29-46. In Suma Etnológica Brasileira - Volume 1: Etnobiologia, Berta G. Ribeiro, coord.,. Petrópolis, Vozes; FINEP.

Lozada, M.; Ladio, A. \& Weigandt, M. 2006. Cultural transmission of ethnobotanical knowledge in a rural community of northwestern Patagonia, Argentina. Economic Botany 60: 374-385.

Medeiros, M.F.T.; Fonseca, V.S.; Andreata, R.H.P. 2004. Plantas medicinais e seus usos pelos sitiantes da Reserva Rio das Pedras, Mangaratiba, RJ, Brasil. Acta Botanica Brasilica 18(2): 391-399.

Mendonça, R.C.; Felfili J.M., B.M.T. Walter; Silva Júnior M.C.; Rezende A.V; Filgueiras T.S. \& Silva P.E.N. 1998. Flora vascular do cerrado. Pp. 288-556. In: Sano, S.M., \& Almeida, SD. P. Cerrado: ambiente e flora. Planaltina, Embrapa-CPAC.

Milliken, W \& Albert, B. 1996. The use of medicinal plants by the Yanomami Indians of Brazil. Economic Botany 50(1):10-25.
Ming, L.C. \& Junior, A.A. 2005. Aspectos Etnobotânicos de Plantas Medicinais na Reserva Extrativista "Chico Mendes". Florística e Botânica Econômica do Acre, Brasil. The New York Botanical Garden. Disponível em: http://www.nybg.org/bsci/acre/www1/medicinal.html

Miranda, T.M. \& Hanazaki, N. 2008. Conhecimento e uso de recursos vegetais de restinga por comunidades das ilhas do Cardoso (SP) e de Santa Catarina (SC), Brasil. Acta Botanica Brasilica 22: 203-215.

Nunes G.P.; Silva M.F.; Resende U.M. \& Siqueira J.M. 2003. Plantas medicinais comercializadas por raizeiros no Centro de Campo Grande, Mato Grosso do Sul. Revista Brasileira de Farmacognosia 13: 83-92.

Oliveira, F.C.; Albuquerque, U.P.; Fonseca-Kruel, V.S. \& Hanazaki, N. 2009. Avanços nas pesquisas etnobotânicas no Brasil. Acta Botanica Brasilica 23(2): 590-605.

Oliveira, G.L.; Oliveira, A.F.M. \& Andrade, L.H.C. 2010. Plantas medicinais utilizadas na comunidade urbana de Muribeca, Nordeste do Brasil. Acta Botanica Brasilica 24(2): 571-577.

Pagotto, T.C.S.; Camilotti, D.C.; Longo, J.M.; Souza, P.R. 2006. Bioma Cerrado e área estudada. Pp.18-30 In: Pagotto, T.C.P., Souza, P.R (Eds.). Biodiversidade do Complexo Aporé-Sucuriú - Subsídios à conservação e manejo do bioma Cerrado. Campo Grande, Ed. UFMS.

Pasa, M.C.; Soares, J.J., Guarim Neto, G. 2005. Ethnobotany study in community of Conceição-Açu (on the upper basin of the River Aricá Açu, MT, Brazil). Acta Botanica Brasilica 19(2): 195-207.

Phillips, O. \& Gentry, A. H.1993. The Useful Plants of Tamboapata, Peru: II. Additional Hypothesis Testing in Quantitative Ethnobotany. Economic Botany 47: 33-43.

Pilla, M.A.C.; Amorozo, M.C.M. \& Furlan, A. 2006. Obtenção e uso das plantas medicinais no distrito de Martim Francisco, Município de Mogi-Mirim, SP, Brasil. Acta Botanica Brasilica 20(4): 789-802.

Pinto, E.P.P.; Amorozo, M.C.M. \& Furlan, A. 2006. Conhecimento popular sobre plantas medicinais em comunidades rurais de mata atlântica Itacaré, BA, Brasil. Acta Botanica Brasilica 20(4): 751-762.

Pott, A.; Pott, V.J. 1994. Plantas do Pantanal. Brasília, Embrapa.

Prance, G.T. 1987. Etnobotânica de algumas tribos Amazônicas. Pp. 119-133. In: Ribeiro, D. (Ed.). Suma Etnológica Brasileira. Vol. 1. Etnobiologia. 2 ed. São Paulo, Vozes/FINEP.

Santos, J.F.L.; Amorozo, M.C.M.; Ming, L.C. 2008. Uso de plantas medicinais na comunidade rural da Vargem Grande, município de Natividade da Serra, SP. Revista Brasileira de Plantas Medicinais 10(3): 67-81.

Schardong, R.M.F. \& Cervi, A.C. 2000. Estudos etnobotânicos das plantas de uso medicinal e místico na comunidade de São Benedito, bairro São Francisco, Campo Grande, MS, Brasil. Acta Biológica Paranaense 29(1/4): 187-217.

Scheffer, M.C., Ming, L.C., Araújo, A.J. 1999. Conservação de recursos genéticos de plantas medicinais. In: Queiróz, M.A. de; Goedert, C.O.; Ramos, S.R.R. (Eds.). Recursos Genéticos e Melhoramento de Plantas para o Nordeste brasileiro. (on line). Petrolina, Embrapa Semi-Árido/Brasília-DF: Embrapa Recursos Genéticos e Biotecnologia. Disponível: http://www.cpatsa.embrapa.br.

Silva, C.S.P.; Proença, C.E.B. 2008. Uso e disponibilidade de recursos medicinais no município de Ouro Verde de Goiás, GO, Brasil. Acta Botanica Brasilica 22(2): 481-492.

Souza, L.F. 2007. Recursos vegetais usados na medicina tradicional do Cerrado (comunidade de Baús, Acorizal, MT, Brasil). Revista Brasileira de Plantas Medicinais 9(4): 44-54.

Souza, V.C. \& Lorenzi, H. 2005. Botânica Sistemática. Guia ilustrado para identificação das famílias de Angiospermas da flora brasileira, baseado em APG II. Nova Odessa, Instituto Plantarum de Estudos da Flora Ltda.

Vila Verde, G.M.; Paula, J.R. \& Caneiro, D.M. 2003. Levantamento etnobotânico das plantas medicinais do cerrado utilizadas pela população de Mossâmedes (GO). Revista Brasileira de Farmacognosia 13: 64-66. 